University of Wollongong

Research Online

Faculty of Engineering and Information

Faculty of Engineering and Information

Sciences - Papers: Part B

Sciences

2017

Dosimetric evaluation near lung and soft tissue interface region during respiratory-gated and non-gated radiotherapy: A moving phantom study

Weiloong Jong

University of Malaya

Ngiemin Ung

University of Malaya

Ath Vannyat

University of Malaya

Anatoly B. Rosenfeld

University of Wollongong, anatoly@uow.edu.au

Jeannie Hsiu Ding Wong

University of Malaya

Follow this and additional works at: https://ro.uow.edu.au/eispapers1

Part of the Engineering Commons, and the Science and Technology Studies Commons

Research Online is the open access institutional repository for the University of Wollongong. For further information contact the UOW Library: research-pubs@uow.edu.au 


\title{
Dosimetric evaluation near lung and soft tissue interface region during respiratory-gated and non-gated radiotherapy: A moving phantom study
}

\author{
Abstract \\ Challenges in treating lung tumours are related to the respiratory-induced tumour motion and the \\ accuracy of dose calculation in charged particle disequilibrium condition. The dosimetric characteristics \\ near the interface of lung and Perspex media in a moving phantom during respiratory-gated and non- \\ gated radiotherapy were investigated using Gafchromic EBT2 and the MOSkin detector. The MOSkin \\ detectors showed good agreement with the EBT2 films during static and gated radiotherapy. In static \\ radiotherapy, the penumbral widths were found to be $3.66 \mathrm{~mm}$ and $7.22 \mathrm{~mm}$ in Perspex and lung media, \\ respectively. In non-gated (moving) radiotherapy with $40 \mathrm{~mm}$ respiratory amplitude, dose smearing effect \\ was observed and the penumbral widths were increased to $28.81 \mathrm{~mm}$ and $26.40 \mathrm{~mm}$, respectively. This \\ has been reduced to $6.85 \mathrm{~mm}$ and $9.81 \mathrm{~mm}$, respectively, in gate d radiotherapy with 25\% gating window. \\ There were still some dose discrepancies as compared to static radiotherapy due to the residual motion. \\ This should be taken into account in the margin generation for the target tumour.

\section{Disciplines} \\ Engineering | Science and Technology Studies

\section{Publication Details} \\ Jong, W. L., Ung, N. M., Vannyat, A., Rosenfeld, A. B. \& Wong, J. H.D. (2017). Dosimetric evaluation near \\ lung and soft tissue interface region during respiratory-gated and non-gated radiotherapy: A moving \\ phantom study. Physica Medica: an international journal devoted to the applications of physics to \\ medicine and biology, 42 39-46.
}




\title{
Dosimetric evaluation near lung and soft tissue interface region during respiratory- gated and non-gated radiotherapy: A moving phantom study
}

\author{
W L Jong ${ }^{1}$, N M Ung ${ }^{1}$, Ath Vannyat ${ }^{1,2}$, A B Rosenfeld ${ }^{3}$, J H D Wong ${ }^{4,5}$ \\ ${ }^{1}$ Clinical Oncology Unit, Faculty of Medicine, University of Malaya, Kuala Lumpur, \\ Malaysia \\ ${ }^{2}$ Oncology Department, Calmette Hospital, Phnom Penh, Cambodia \\ ${ }^{3}$ Centre for Medical Radiation Physics, University of Wollongong, Wollongong, Australia. \\ ${ }^{4}$ Department of Biomedical Imaging, Faculty of Medicine, University of Malaya, Kuala \\ Lumpur, Malaysia \\ ${ }^{5}$ University of Malaya Research Imaging Centre, Faculty of Medicine, University of Malaya, \\ Kuala Lumpur, Malaysia
}

Email: nmung@ummc.edu.my

\begin{abstract}
Challenges in treating a lung tumour are related to the respiratory-induced tumour motion and the accuracy of the treatment planning dose calculation in non-CPE conditions. The dosimetric characteristics across the interface of lung and Perspex media in a moving phantom during static, respiratory-gated and non-gated (moving) radiotherapy was investigated using Gafchromic EBT2 and the MOSkin detector. The MOSkin detectors showed a good agreement with the EBT2 film in the dose profile measurement during static and gated radiotherapy. In static radiotherapy, the penumbral widths in Perspex and lung media were found to be $3.66 \mathrm{~mm}$ and $7.22 \mathrm{~mm}$, respectively. In non-gated (moving) radiotherapy, dose smearing effect was observed and the penumbral widths were increased to $28.81 \mathrm{~mm}$ and $26.40 \mathrm{~mm}$, respectively with $40 \mathrm{~mm}$ respiratory amplitude. This effect has been reduced in gated radiotherapy with $25 \%$ gating window's width, with the penumbral widths of $6.85 \mathrm{~mm}$ and $9.81 \mathrm{~mm}$, respectively. There were still some dose discrepancies as compared to static radiotherapy due to the residual motion. The dose discrepancies should be taken into account in the margin generation for the target tumour. The accuracy of different dose calculation algorithms near interface region was evaluated. It was found that the root mean square error of $6.21 \%, 3.32 \%, 2.62 \%$, and $1.73 \%$ were found for pencil beam convolution, analytical anisotropic algorithm, Acuros XB (dose to water), and Acuros XB (dose to medium), respectively compared to EBT2 measured dose across the interface region. It was also found that the over-estimation of the dose coverage will lead to the choice of small field size and thus, under-dosage to the tumour. For better dose calculation accuracy near interface region, better dose calculation algorithms such as analytical anisotropic
\end{abstract}


algorithm or Acuros XB are essential. A better understanding and selection of the dose calculation algorithms is very important.

\section{Introduction}

Lung stereotactic body radiotherapy (SBRT) enables high radiation dose ( 60 Gy) to be delivered hypo-fractionally to the target tumour while minimizing dose to surrounding healthy tissues [1]. Accuracy and precision are needed to ensure high tumour control probability while low normal tissue complication. However, when treating a lung tumour, tumour motion exists due to involuntary respiratory motion. Previous studies found that the tumour motion is greater along the cranial-caudal direction, with an average displacement of $12 \mathrm{~mm}[2,3]$. The positional change of the lung tumour leads to dosimetric uncertainty such as dose smearing effect such as blurring and deformation of the dose distribution [4], results in detrimental effect of the therapeutic ratio.

When the lung tumour has displacement of more than $5 \mathrm{~mm}$, The AAPM Task Group 76 recommended that respiratory management techniques namely motion-encompassing, breathholding, forced-shallow-breathing, gating and tracking method be considered [5-8]. In motion-encompassing technique, additional safety margin of clinical target volume (CTV) is needed to ensure adequate dose coverage to the target tumour, similar to various systematic uncertainties chain in radiotherapy such as patient setup. However, this will potentially increase the normal tissue complication probability because of larger normal tissue involvement.

By considering the respiratory motion and utilising gating technique or real time motion adaptive radiotherapy, the safety margin for intra-fractional tumour motion can be reduced. While real time motion adaptive radiotherapy utilizing image guidance and dynamic multi leaf collimator for treatment such as lung tumour was proven as an attractive option to minimize CTV margins [9, 10]. However, it is still not available for many radiotherapy facilities. Gating technique is an interrupting irradiation technique, where the radiation is delivered on and off during the pre-defined phase (gating windows) of the respiratory cycle. Whilst respiratory gating technique is good in managing the tumour motion, some tumour motion (known as residual tumour motion) still occurs within the gating window [11]. The selection of the gating window's width is a trade-off between residual tumour motion and treatment time $[8,11-14]$. Increasing the gating window's width will increase the duty cycle (shorten the treatment time), but also result in greater residual tumour motion as a larger proportion of the total tumour motion will be captured [15]. The residual tumour motion may contribute to dosimetric error [16]. Thus, a safety margin is still needed.

Another issue in treating the lung tumour is with regards to the accuracy of treatment planning dose calculation. Lung tumours assumed that often embedded in low density lung tissues, which the density is between $0.19-0.35 \mathrm{~g} / \mathrm{cm}^{3}$ [17]. Achievement of high accuracy in dose calculation for lung SBRT is always challenging due to the lack of lateral electron equilibrium near the lung and soft tissue interface. The choice of dose calculation algorithms in treatment planning system (TPS) becomes particularly important especially for the radiotherapy of tissues with large inhomogeneity. Advanced algorithms such as anisotropic analytical algorithm (AAA) and Acuros XB (AXB) are recommended for dose calculation in inhomogeneous and interface region such as lung [18-22]. The older algorithms such as pencil beam convolution (PBC) may show deviation between actual and calculated dose in 
the order of $20-30 \%[19,21]$. The uncertainties due to dose calculation algorithms were not accounted in the margins generated to form CTV.

Generally, the margin for CTV is a geometrical concept that taking into consideration the geometrical variations such as tumour motion to ensure adequate dose coverage to the lung tumour. However, it is known that the lack of electronic equilibrium at the interface between the low density lung and the tumour causes an under-dosage at the periphery of the tumour [23]. It is clinically important to characterise dosimetric uncertainties due to respiratory motion near the interface of the lung and tumour.

Alhakeem et al. have investigated the interface dosimetry using several dosimetric techniques including a MOSFET-based detector, the MOSkin detector [20]. They used the MOSkin detector to study the depth dose near the interface region of water and air, water and steel, and water and lung. They found that the MOSkin measurement is in good agreement with Monte Carlo calculation, except at the interface with steep dose gradient due to the volume averaging effect of the voxels in Monte Carlo calculation. They concluded that a detector such as the MOSkin detector with small sensitive volume and tissue-equivalent materials could provide accurate dose assessment near the interface region of two different media.

In this study, the dosimetric characteristics across the lung and Perspex interface on a moving phantom has been investigated, which simulated a moving tumour's interface or lung and soft tissue interface. Specifically, the dosimetric characteristics across the lung and soft tissue interface during respiratory-gated radiotherapy were experimentally assessed using radiochromic film and the MOSkin detectors. The possible margin reduction using respiratory-gated technique was investigated. The dosimetric accuracy of the TPS dose calculation algorithms for lung and soft tissue interface was also evaluated.

\section{Materials and Methods}

\subsection{Experimental setup}

All measurements were carried out under $6 \mathrm{MV}$ photon with $1000 \mathrm{MU} / \mathrm{min}$ using a Novalis Tx linear accelerator (Varian Medical System, Palo Alto, CA) equipped with Exactrac gating system (BrainLAB AG, Heimstetten, Germany). The Exactrac gating system used an illuminator to emit infrared toward the infrared reflective (IR) markers attached on the phantom or patient. Two cameras was used to track the motion of the reflective markers on the phantom [24]. A delay of $1.05 \mathrm{~mm}$ of the gating system and the radiation beam trigger was found in our previous work [25],

A Perspex slab-based IMRT dose verification phantom positioned on a respiratory gating platform (Standard Imaging, Middleton, WI) was used. Two slab of Perspex slab with lung equivalent insert ( $3 \mathrm{~cm}$ thick for each slab) was sandwiched with a Perspex slab on top and two Perspex slab at the bottom (Figure 1). Since the respiratory motion is usually most pronounced in the cranial-caudal direction [2], the phantom was positioned and set to move in horizontal direction to mimic lung motion in the cranial-caudal direction. An in-house customised platform capable of moving in the vertical direction was designed and attached to the respiratory gating platform to mimic the respiratory-induced chest wall motion. The 
pattern of the respiratory movement followed a sine function and there was no offset between the vertical and horizontal motion. Five IR markers were positioned on the vertical platform as external surrogates for respiratory motion tracking. This phantom combination is henceforth called as "moving phantom”.

Considering the moving phantom possesses similar tissue heterogeneity to the lung and soft tissue, the dosimetric characteristic across the lung and Perspex interface of the moving phantom was assessed. The radiation detectors were positioned in between the Perspex slabs with lung inserts and at the lung and Perspex interface. The lung and Perspex interface of the moving phantom at its home position (middle position between the peaks of the respiratory amplitude) was aligned in coincidence with the radiation isocentre and was exposed with a single direct beam (Figure 1). The proportion of the movement in both lung and Perspex media is equally distributed. Three types of irradiations were simulated: phantom in nonmoving state with continuous irradiation, phantom in moving state with continuous irradiation and phantom in moving state with gated irradiation. For simplicity, these irradiations will be referred as static radiotherapy, non-gated radiotherapy, and gated radiotherapy, respectively. Details of the respiratory operation's parameters are shown in Table 1.

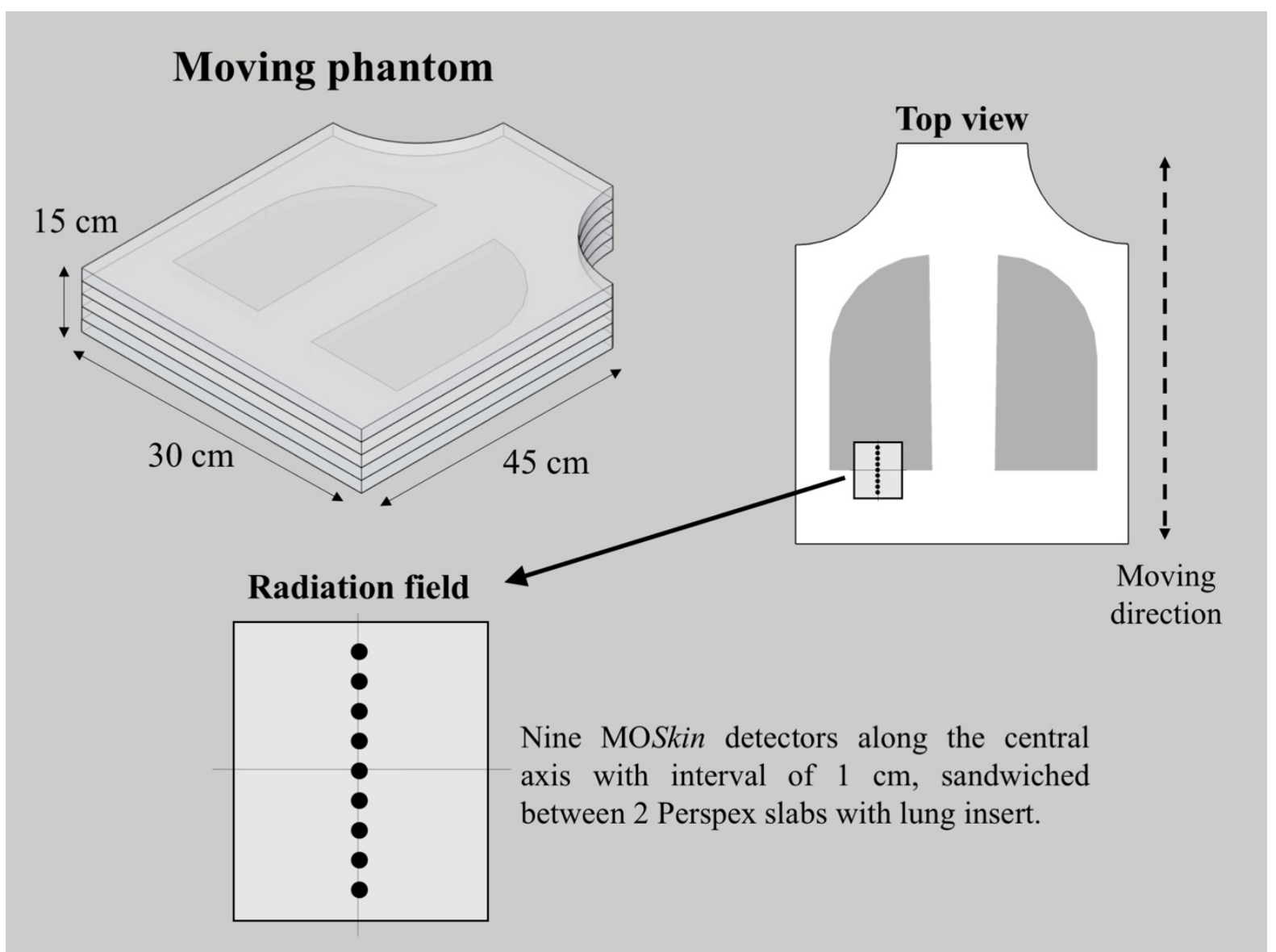

Figure 1. Perspex slabs IMRT dose verification phantom with lung equivalent insert was sandwiched with the Perspex slabs. The interface of the lung and Perspex media was irradiated with $6 \mathrm{MV}$ photon beam with $4 \times 3 \mathrm{~cm}^{2}$ field size. The dots indicate the positions of the MOSkin detectors sandwiched in between 2 Perspex slabs with lung insert. 
Table 1. Respiratory operation's parameters during static, non-gated and gated radiotherapy.

\begin{tabular}{lll}
\hline & Amplitudes & Gating windows (range) \\
\hline Static & $0 \mathrm{~mm}$ & - \\
Non-gated & $10 \mathrm{~mm}, 20 \mathrm{~mm}$, and $40 \mathrm{~mm}$ & - \\
Gated & $10 \mathrm{~mm}, 20 \mathrm{~mm}$, and $40 \mathrm{~mm}$ & $\begin{array}{l}25 \% \quad(37.5 \%-62.5 \%), 50 \% \quad(25 \%- \\
\end{array}$ \\
\end{tabular}

\subsection{Gafchromic EBT2 film and the MOSkin detector}

Selection of a suitable detector is very important to characterise the lung and soft tissue interface dosimetry. The size of the detector must be small, especially the sensitive volume in order to provide high spatial resolution. In this work, Gafchromic EBT2 film (International Specialty Products, Wayne, NJ) and MOSkin detector were used to measure the dose near the lung and Perspex interface. The EBT2 films were cut into sizes of 40 (lateral) x 50 (longitudinal) $\mathrm{mm}^{2}$ for dose profile measurement. All films were placed in landscape orientation at the centre of an Epson Expression 10000XL flatbed scanner (Epson America, Long Beach, CA) to reduce film and scanner-induced change in pixel values. The films were scanned in RGB format with a resolution of 96 pixels per inch. A median filter of $5 \times 5$ pixels was applied. Only the red channel was used for analysis. Image analysis was performed using ImageJ version 1.43U (National Institute of Health, Bethesda, MD). The overall uncertainty for EBT2 film for dose measurement in radiotherapy was 2.8\% (1 SD) [26].

MOSkin detector, a special design of p-MOSFET-based detector, developed at the Centre for Medical Radiation Physics, University of Wollongong, Australia. The silicon chip with dimension of $0.6 \times 0.8 \times 0.35 \mathrm{~mm}^{3}$ is “dropped-in” a kapton pigtail strip and was sealed with a layer of thin polyamide film with water-equivalent thickness of $0.07 \mathrm{~mm}$. The MOSkin detector is known for its capability for skin dose measurement [27-29]. It is also suitable for dose measurement in steep dose gradient region such as small radiation field [30] and interface [20] due to its small sensitive volume $\left(0.002 \mathrm{~mm}^{3}\right)$, water-equivalent packaging, and minimal perturbation effect. Additional, it also has the ability of instant or real-time readout. In this work, together with EBT2 film, the MOSkin detectors were used as an independent check for interface dosimetry. The agreement between the MOSkin and EBT2 film measurement was evaluated using:

$$
R M S E=\sqrt{\frac{\sum\left(D-D_{E B T 2}\right)^{2}}{n}}
$$

\section{Equation 1}

where $R M S E$ is the root mean square error, $D$ is the MOSkin detector measured dose and $D_{E B T 2}$ is the EBT2 film measured dose over the nine measurement points $(n)$.

\subsection{Output constancy}


Both EBT2 films and the MOSkin detectors were calibrated in a solid water phantom under the linear accelerator with $6 \mathrm{MV}$ photon beam at source to surface distance of $100 \mathrm{~cm}$ and field size of $10 \times 10 \mathrm{~cm}^{2}$. The films and detectors were always in 'face-up' orientation to avoid dosimetric error due to asymmetric structure of the detectors. A set of standard film were irradiated to establish a calibration curve (dose range from 0 to $1000 \mathrm{cGy}$ ) for EBT2 film while an average calibration factor of $2.323 \pm 0.115 \mathrm{mV} \mathrm{cGy}^{-1}$ was used for all MOSkin detectors.

Before evaluating the dosimetric characteristics near the interface region, the radiation output constancy of a linear accelerator in non-gated or gated operation has to be assessed. According to AAPM Task Group 142, the radiation output of a linear accelerator should be within $\pm 2 \%$ during gated operation as compared to standard radiation delivery (static radiotherapy) [31].

The dosimetric comparison of gated and non-gated mode of a linear accelerator was performed. The lung inhomogeneity slab of the moving phantom was replaced with Perspex slab. Two hundred monitor units were delivered for all irradiation conditions. The radiation output at the isocentre was measured with the EBT2 film and the MOSkin detector at depth of $6 \mathrm{~cm}$ in the moving phantom. The average of the central $5 \times 5$ pixels area around the central axis of the film was taken and analysed. All measurements were repeated twice.

\subsection{Dose profile measurement}

EBT2 film and the MOSkin detectors were used to measure the dose profile at depth of $6 \mathrm{~cm}$ (between the Perspex slabs with lung insert) in the moving phantom along the longitudinal direction across the lung and Perspex interface. Nine MOSkin detectors were used and positioned along the centre axis of the radiation beam with interval of $5 \mathrm{~mm}$ between the detectors, with one detector at the isocentre (Figure 1). The positioning accuracy of the MOSkin detector is estimated to be within $\pm 1 \mathrm{~mm}$. All MOSkin measured dose profiles were normalised to the dose measured with the MOSkin detector at the central axis of the radiation beam while EBT2 dose profiles were normalised to the average of the central $5 \times 5$ pixels area around the central axis. This is to aid the identification of the desired isodose level for evaluation. The penumbral width of the dose profile for non-gated/gated and static radiotherapy were calculated to evaluate the dosimetric properties.

\subsection{Dose calculation near interface region}

In addition to experimental measurements, dose profiles along the longitudinal direction across the lung and Perspex interface of the phantom were calculated in an Eclipse TPS (Varian Medical System, Palo Alto, CA). Three dose calculation algorithms available in Eclipse TPS were used: PBC version 10.0.28 with modified batho, AAA version 13.6.23 and AXB version 13.6.23. These algorithms shared the same photon beam data, which were acquired using a CC13 ionisation chamber in a water phantom (Blue Phantom, IBA).

The moving phantom was scanned with a big bore computed-tomography (CT) scanner (Brilliance CT Big Bore, Philips Healthcare, Andover, MA) with slice thickness of $1.0 \mathrm{~mm}$ 
and pitch of 1 . The image set were then imported into the TPS. The calculations were scored with resolution of $1 \mathrm{~mm}$ (smallest of $1.25 \mathrm{~mm}$ for PBC). For PBC and AAA, the dose in water was reported. For $\mathrm{AXB}$, the dose was reported as dose in water and medium $\left(\mathrm{AXB}_{\mathrm{w}}\right.$ and $\mathrm{AXB}_{\mathrm{m}}$ ). The calculated dose profiles were compared against experimental measurement using EBT2 film and the MOSkin detectors. Quantitative evaluation of the agreement between The TPS calculated dose $(D)$ and the experimental measurement using EBT2 film $\left(D_{E B T 2}\right)$ was performed using the root mean square error (RMSE).

\section{Results and discussion}

\subsection{Output constancy}

Figure 2 shows the measured radiation output of the linear accelerator under static, gated and non-gated radiotherapy. All measured doses were normalised to 1 at the EBT2 film measured dose during static radiotherapy. In static radiotherapy, the measured doses at the isocentre of the radiation beam were $144.92 \pm 1.58$ cGy and $145.69 \pm 1.96$ cGy with EBT2 film and the MOSkin detector, respectively.

In non-gated radiotherapy, the radiation output measured with EBT2 film for $20 \mathrm{~mm}$ and $40 \mathrm{~mm}$ respiratory amplitudes were lower with deviation of $-6.5 \%$ and $-17.9 \%$, respectively. No significant difference was observed for $10 \mathrm{~mm}$ respiratory amplitude. When the radiation was delivered in gated mode (25\% gating window's width), the radiation outputs corresponded well to static radiotherapy with the deviation of $<2 \%$. Gated radiotherapy with gating window' width of $50 \%$ and $75 \%$ shows deviation of $4.8 \%$ and $9.4 \%$, respectively. This shows that the gated radiotherapy reduced the effect of respiratory motion on dose delivery accuracy during non-gated radiotherapy. However, larger gating window's width retains the residual motion, thus reduced the dose delivery accuracy.

Meanwhile, the agreement of between the MOSkin and EBT2 film measurement for radiation output constancy was also evaluated (Figure 2). Similarly, the MOSkin detector was found to be in good agreement with EBT2 film measurement during static radiotherapy and gated radiotherapy with different respiratory amplitudes, with the deviations of $<2 \%$, except for $40 \mathrm{~mm}$ respiratory amplitudes (>3\%). 


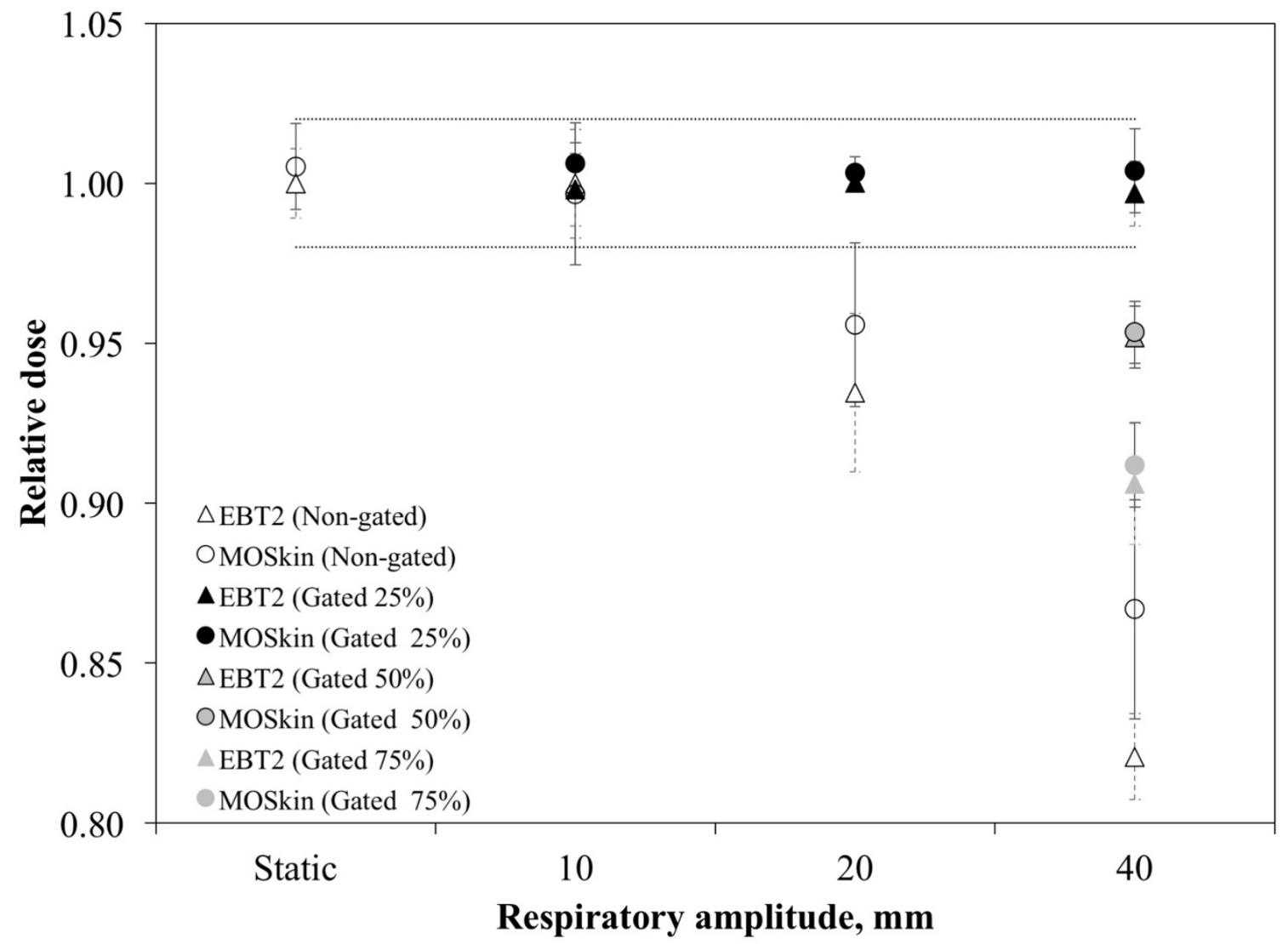

Figure 2.Radiation output constancy during respiratory-gated radiotherapy using both MOSkin detector and EBT2 film. The error bars show 1 SD of 3 repeated measurement.

\subsection{Dose profile during static, non-gated radiotherapy and gated radiotherapy}

Figure 3 shows an example of the measured dose distribution using EBT2 film during static (no motion), non-gated and gated radiotherapy. In the case of non-gated radiotherapy, the moving phantom was set to move with motion amplitude of $40 \mathrm{~mm}$. Comparing to static radiotherapy, there was a significant difference in the dose distribution. In non-gated radiotherapy, dose smearing effect was illustrated at the edge of the dose distribution along the moving direction, leads to the blurring of the high dose gradient region at the edge of the radiation field (penumbra region). Dose decrement was observed inside the radiation field while dose increment was observed outside the radiation field, results in under-dosage inside the target tumour while overdosing the surrounding tissue. Figure 4 demonstrates the measured dose profile along the longitudinal direction during static, non-gated, and gated radiotherapy with different tumour motion amplitudes. Similar to Figure 3, dose smearing effect was observed in non-gated radiotherapy and this dose smearing effect is more pronounced with the increasing in the respiratory amplitude.

Unlike non-gated radiotherapy, the dose smearing effect has been reduced during gated radiotherapy with gating window's width of $25 \%$. The delivered dose distributions during gated radiotherapy and static radiotherapy are similar. However, there is still some dose discrepancies of the dose profile due to the residual motion within the gating window during 
gated radiotherapy compared to static radiotherapy [16]. The residual tumour motion in the gating windows is dependent on the width of the gating window and the respiratory amplitude [7, 12, 16]. The residual motion is greater when the gating window's width increased, results in more pronounced dose smearing effect as shown in Figure 5. If the gating window is $100 \%$, implying there is no gating, the residual tumour motion can be very large as in non-gated radiotherapy. Smaller gating window should be used in order to retain accurate dose distribution. However, this will prolong the treatment time. Falk et al. reported that the treatment time for amplitude-based gated SBRT is 3.5 times longer than non-gated radiotherapy [16].

The dose profiles were measured with the MOSkin detectors during respiratory-gated radiotherapy and compared against EBT2 film measured profiles as shown in Figure 4. The MOSkin measured dose profiles corresponded well with the EBT2 film measurement during static radiotherapy and gated radiotherapy, with the RMSE of $<3 \%$. The result is consistent with the reported result in previous studies who used MOSFET in lung and water interface [20, 32]. Alhakeem et al. have found the difference between the MOSkin measurement and Monte Carlo (MC) simulation was within $\pm 3 \%$ for depth dose measurement near lung and water interface in a lung and water phantom [20].

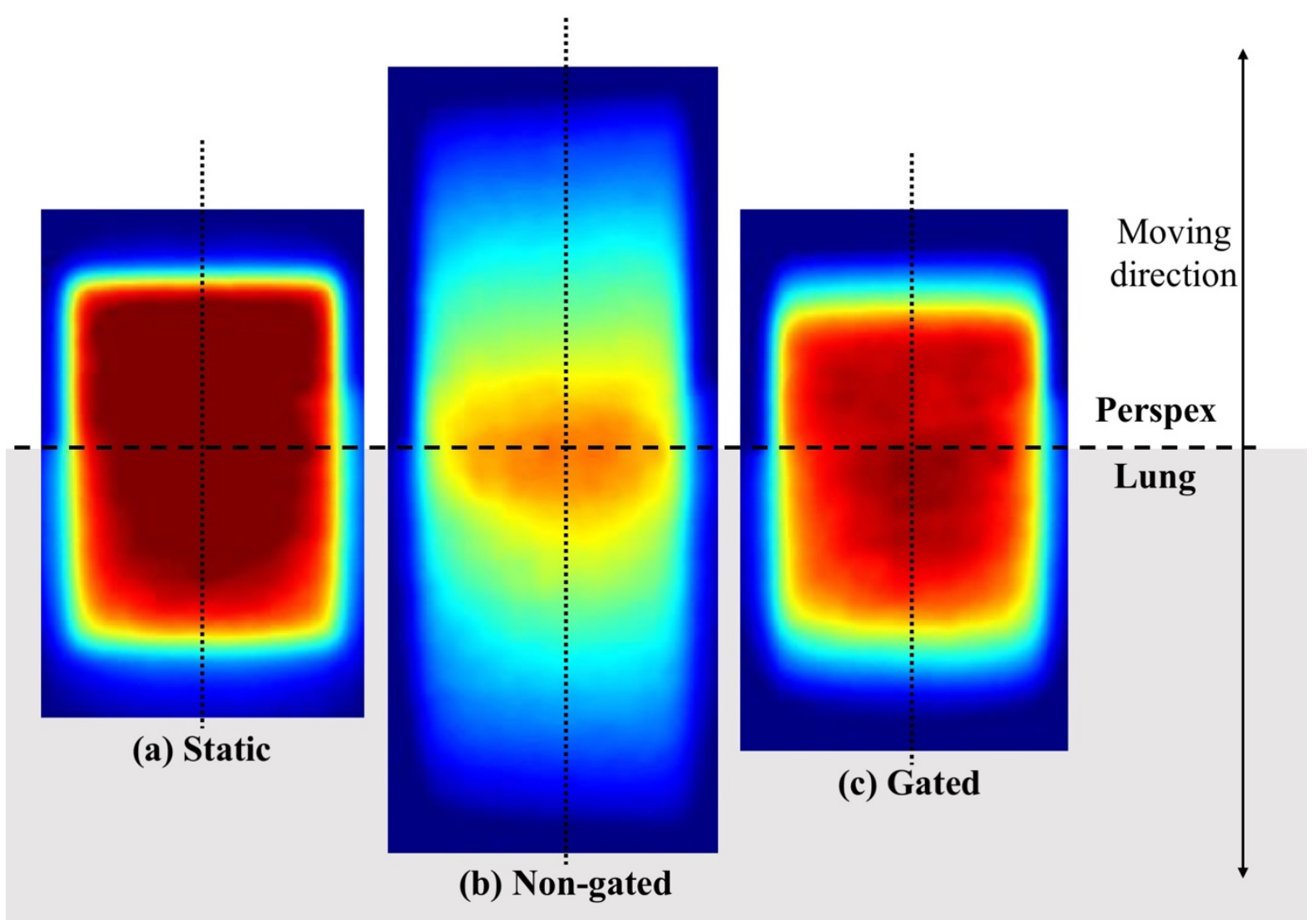

Figure 3. Measured dose distribution using EBT2 film across the lung and Perspex interface during static radiotherapy (no motion), non-gated radiotherapy (motion amplitude of $40 \mathrm{~mm}$ ) and gated radiotherapy(motion amplitude of $40 \mathrm{~mm}$ ). The vertical dot line indicates the measured dose profile along the central of the radiation field in each case. 
(a) Static

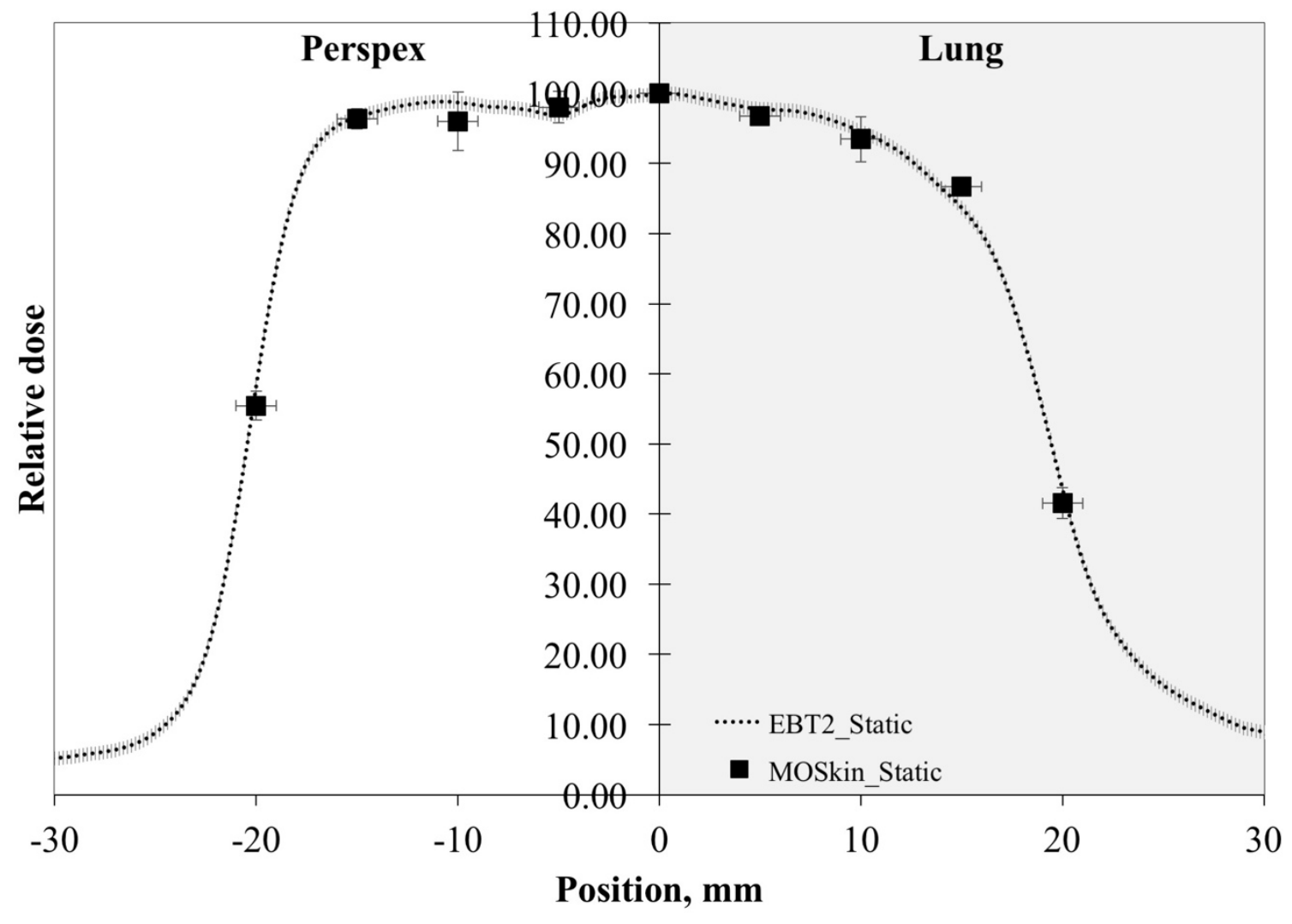

(b) $10 \mathrm{~mm}$ respiratory amplitude

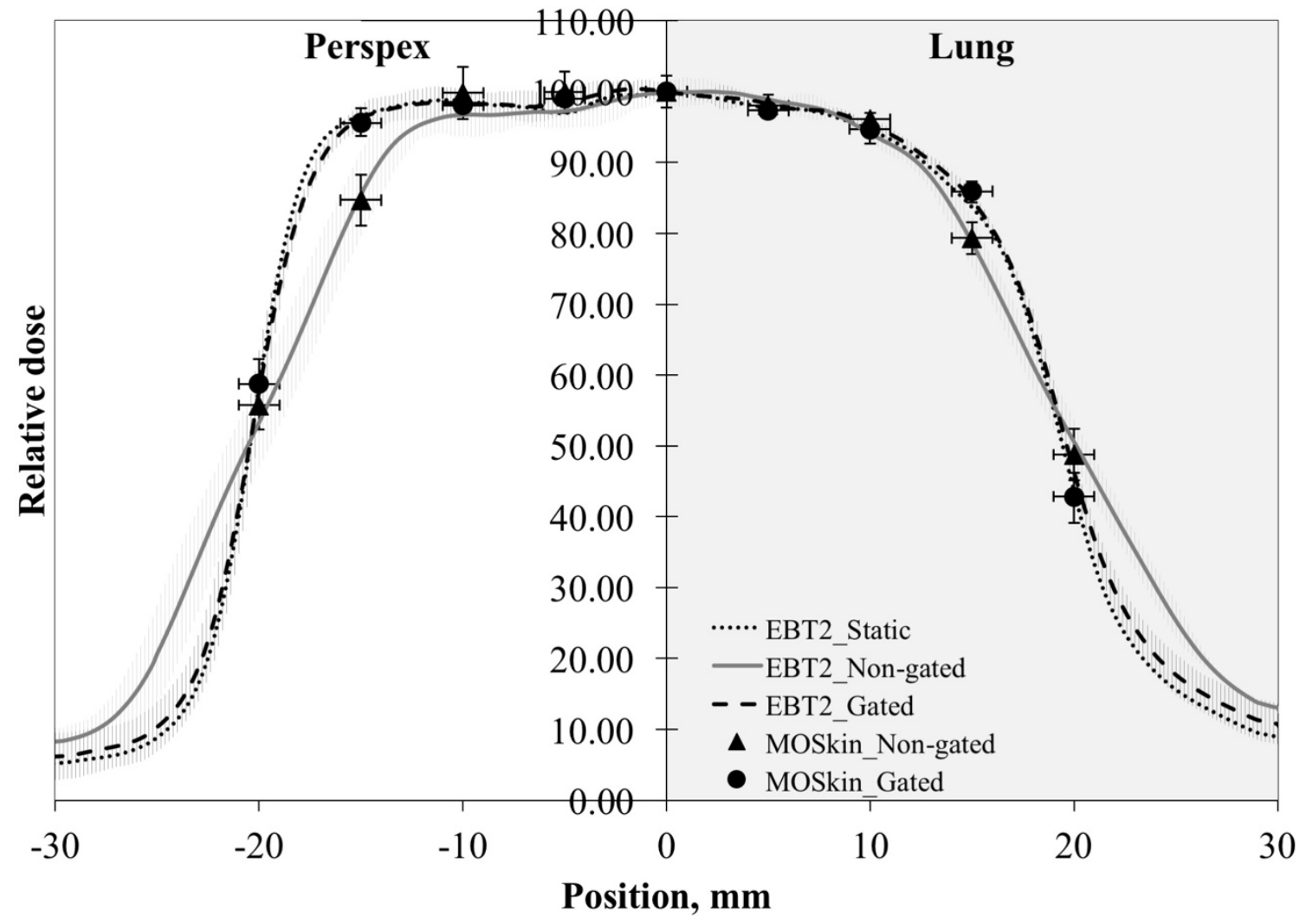


(c) $20 \mathrm{~mm}$ respiratory amplitude

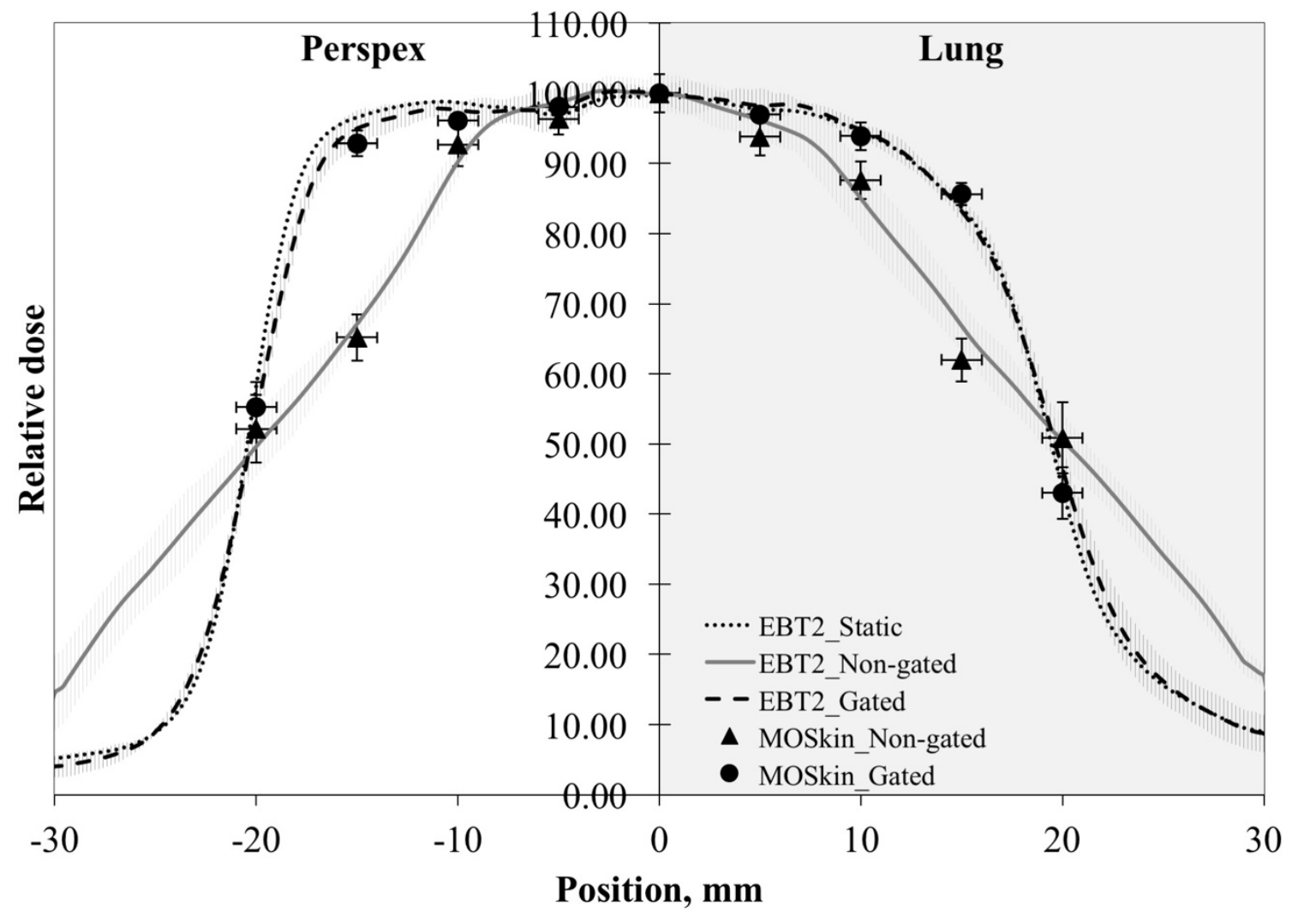

(d) $40 \mathrm{~mm}$ respiratory amplitude

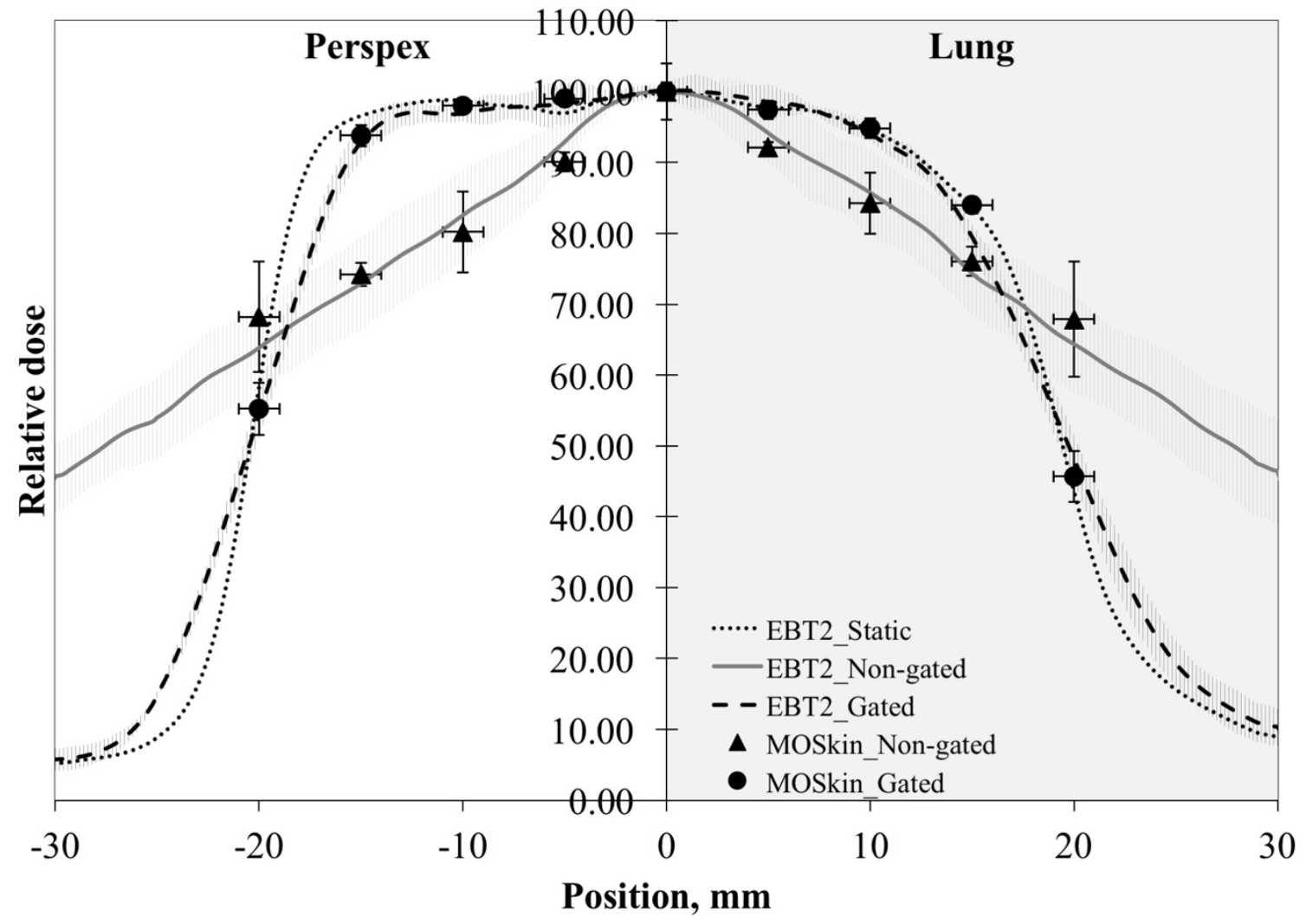


Figure 4. Dose profiles measured with EBT2 film and the MOSkin detectors during static (a), non-gated and gated radiotherapy with tumour motion amplitude of $10 \mathrm{~mm}$ (b), $20 \mathrm{~mm}$ (c), and $40 \mathrm{~mm}(d)$. The vertical error bar shows 1 SD of three repeated measurements for each irradiation condition. The horizontal error bars represent the positioning error of $1 \mathrm{~mm}$ for the MOSkin detector.

\subsection{Penumbral width}

The penumbral width (distance between $20 \%$ and $80 \%$ isodose of the profile) in both the Perspex and lung media was measured and summarised in Table 2. During static radiotherapy, steeper dose gradient (narrower penumbral width) appears in Perspex media than lung media as illustrated in Figure 4. The asymmetrical dose profiles can be explained by the longer range of the lateral scattered electron in the low density media (lung), compared to water equivalent material (Perspex) [33-35]. This resulted in the lateral electronic disequilibrium occurring at a larger distance from the geometrical beam edge in lung media compared to in Perspex media, therefore a decrease in the sharpness of the dose profile (wider penumbral width) was observed in lung media.

When the radiation was delivered in non-gated mode, dose smearing effect appeared. The penumbral widths of the dose profiles were wider in both lung and Perspex media than static radiotherapy. The dose smearing effect was found to be less pronounced in lung media compared to Perspex media with increasing tumour motion amplitudes. This is probably due to respiratory amplitude (phantom motion) used in this study is relatively smaller than the range of the lateral scattered electron in lung media compared to in Perspex media. Assuming the range of scattered electron is equal to the CSDA (continuous slowing down approximation) range [36] of $6 \mathrm{MeV}$ electron, which is $3.162 \mathrm{~g} \mathrm{~cm}^{-2}$ and $3.088 \mathrm{~g} \mathrm{~cm}^{-2}$, respectively in Perspex (density of $\left.1.18 \mathrm{~g} \mathrm{~cm}^{-3}\right)$ and lung $\left(\sim 0.3 \mathrm{~g} \mathrm{~cm}^{-3}\right)$ media. The scattered electron may travel $2.68 \mathrm{~cm}$ laterally in Perspex media and $10.29 \mathrm{~cm}$ in lung media and this distance is assumed to be the starting point of lateral electronic disequilibrium from the geometrical edge of the radiation beam. In the case of $40 \mathrm{~mm}$ respiratory motion in this study (Figure 4(d)), the range of the scattered electron in lung media is relatively greater than the motion, thus, the dose smearing effect is less to the penumbra of the dose profile in lung media compared to Perspex media.

The penumbral width of the dose profiles during gated radiotherapy were significantly reduced. During non-gated radiotherapy with $10 \mathrm{~mm}$ tumour motion amplitude, the penumbral width was $9.13 \mathrm{~mm}$ and $11.52 \mathrm{~mm}$ in Perspex and lung media, respectively. The penumbral width was reduced to $4.26 \mathrm{~mm}$ and $7.92 \mathrm{~mm}$ during gated radiotherapy with 25\% gating window, with an effective reduction of $53 \%$ and $31 \%$, respectively.

For respiratory amplitude of $40 \mathrm{~mm}$, the penumbral widths were reduced from $28.81 \mathrm{~mm}$ and $26.40 \mathrm{~mm}$ to $6.85 \mathrm{~mm}$ and $9.81 \mathrm{~mm}$ in Perspex and lung media, with effective reduction of $76 \%$ and $63 \%$, respectively during gated radiotherapy with $25 \%$ gating window. The effectiveness of respiratory-gated radiotherapy is more pronounced for larger tumour motion amplitude. However, the effectiveness of the gated radiotherapy was decreased as the gating window increased. The residual motion within the gating window results in dosimetric error such as blurring and deformation of the dose distribution and hence, degrade the actual dose distribution especially at the steep dose gradient region. 


\section{Gating windows}

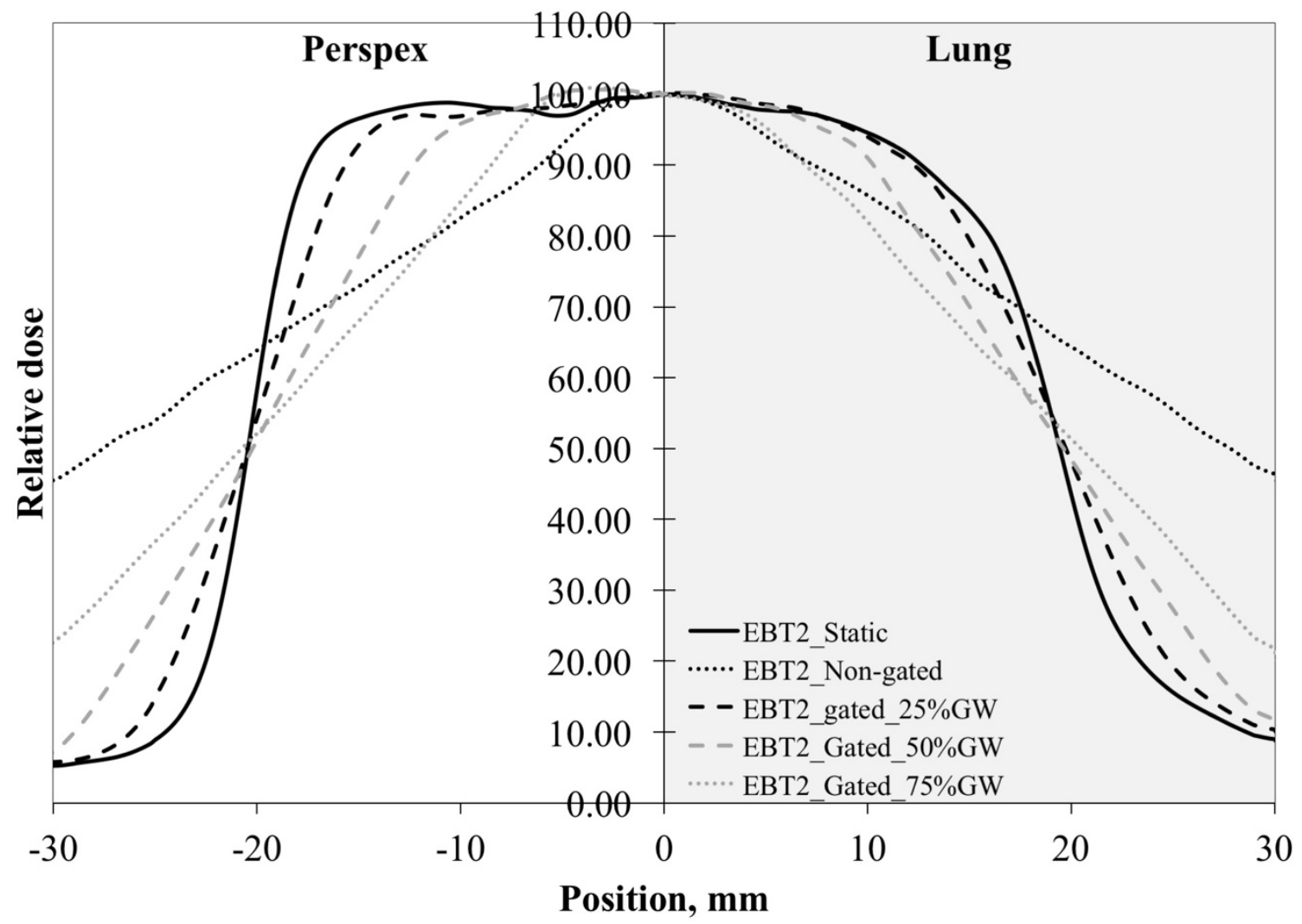

Figure 5. Dose profiles measured with EBT2 film during respiratory static, non-gated and gated radiotherapy with different gating windows' width.

Table 2. Penumbral width of the dose profiles across the lung and Perspex interface during non-gated and gated radiotherapy.

\begin{tabular}{|c|c|c|c|c|c|c|}
\hline & \multicolumn{5}{|c|}{ Penumbra width, mm } \\
\hline & & \multicolumn{2}{|c|}{ Non-gated } & & \multicolumn{2}{|c|}{ Gated } \\
\hline & & Perspex & Lung & & Perspex & Lung \\
\hline \multirow[t]{2}{*}{ Static } & & 3.66 & 7.22 & & & \\
\hline & & & & $\begin{array}{c}\text { Gating } \\
\text { windows }\end{array}$ & & \\
\hline \multirow[t]{5}{*}{ Amplitude } & $10 \mathrm{~mm}$ & 9.13 & 11.52 & $25 \%$ & 4.26 & 7.92 \\
\hline & $20 \mathrm{~mm}$ & 16.53 & 17.37 & $25 \%$ & 4.59 & 7.80 \\
\hline & $40 \mathrm{~mm}$ & 28.81 & 26.40 & $25 \%$ & 6.85 & 9.81 \\
\hline & $40 \mathrm{~mm}$ & & & $50 \%$ & 12.03 & 14.03 \\
\hline & $40 \mathrm{~mm}$ & & & $75 \%$ & 19.42 & 19.49 \\
\hline
\end{tabular}


As demonstrated in Figure 3 and Figure 4, the dose smearing effect due to the respiratory motion resulted in under-dosage inside the target tumour while over-dosage to the surrounding normal tissue, especially with larger respiratory amplitudes. The under-dosage inside the target tumour should be taken into account in radiotherapy. As recommended by AAPM Task Group 76, respiratory management techniques such as motion encompassing or respiratory-gating techniques should be considered when the lung tumour has displacement more than $5 \mathrm{~mm}[5]$.

It is interesting to understand the additional safety margin for respiratory motion needed for motion encompassing technique and also how much margin reduction is possible by using gated radiotherapy. According to Engelsman et al., the margin for intra-fractional respiratory motion is defined as the increase in margin between CTV and planning target volume (PTV) necessary to ensure the same tumour coverage as without intra-fractional motion [37].

In this study, the additional safety margin for the intra-fractional respiratory motion $\left(\mathrm{M}_{\text {resp }}\right)$ was determined by evaluating the agreement between $95 \%$ isodose levels of the dose profiles during non-gated or gated radiotherapy with static radiotherapy in term of dose-todistance agreement (DTA) [38, 39]. The measured margin ( $\left.\mathrm{M}_{\text {resp }}\right)$ was then compared against the calculated margin using van Herk's margin recipe [40, 41]. By accounting the random uncertainties only, the notation that describes the additional margin for the intra-fractional respiratory motion $\left(\mathrm{M}_{\text {resp }}\right)$ is:

$$
\begin{gathered}
M_{\text {resp }}=M_{\text {non-gated } / \text { gated }}-M_{\text {static }} \\
M=\alpha\left(\sigma-\sigma_{p}\right) \\
\sigma=\sqrt{\sigma_{\text {motion }}+\sigma_{\text {setup }}+\sigma_{p}}
\end{gathered}
$$

Equation 2

Equation 3

Equation 4

where $\mathrm{M}$ is the margin during static $\left(M_{\text {static }}\right)$, non-gated $\left(M_{\text {non-gated }}\right)$ or gated radiotherapy $\left(M_{\text {gated }}\right), \alpha$ is the value corresponds to the coverage of the tumour (1.64 for $95 \%$ isodose level, respectively), and $\sigma$ is the quadratic summation of the standard deviation of respiratory motion $\left(\sigma_{\text {motion }}\right)$, setup uncertainty ( $\left.\sigma_{\text {setup }}\right)$, and the width of penumbra $\left(\sigma_{p}\right)$.

The $\sigma_{\text {motion }}$ is assumed to be about 0.4 times the amplitude of respiratory motion, which can be assumed to have a Gaussian probability density function [37]. For $\sigma_{\text {motion }}>5 \mathrm{~mm}$, a correction factor as suggested by Engelsman et al. was applied [37]. Since the proportion of the movement of the moving phantom in lung and Perspex media is equal, the respiratory amplitude will be equalled to half of the total respiratory amplitude. The $\sigma_{\text {setup }}$ is assumed to be $3 \mathrm{~mm}$, which is the typical patient setup error [3]. The $\sigma_{p}$ was obtained based on the penumbral width of the dose profile during static radiotherapy, which is $7.22 \mathrm{~mm}$ and 3.66 $\mathrm{mm}$ in Perspex and lung media, respectively. For gated radiotherapy, the respiratory motion of the moving phantom is uniform. The $\sigma_{\text {motion }}$ of the residual tumour motion was determined since it is known and corresponded to the width of the gating windows.

Table 3 shows the additional margin $\left(M_{\text {resp }}\right)$ for the respiratory motion calculated using van Herk's margin recipe and our measurement. Our measured margins are in good agreement (within $1 \mathrm{~mm}$ difference) with the calculated margins using van Herk's margin recipe, for both non-gated and gated radiotherapy. In non-gated radiotherapy, larger $M_{\text {resp }}$ is required and increased with the respiratory amplitude. 
Compared to non-gated radiotherapy, the measured and calculated margins are much smaller for gated radiotherapy. This shows that the margin reduction was attainable for gated radiotherapy and the dose smearing effect has been reduced. However, small margin is still needed for the residual motion and this residual motion increases with the gating window's width. For example, using 50\% gating window's width for $40 \mathrm{~mm}$ respiratory amplitude requires margins of $4.07 \mathrm{~mm}$ and 2.48 in Perspex and lung media, respectively. The margins increased to $7.02 \mathrm{~mm}$ and $4.64 \mathrm{~mm}$ for $75 \%$ gating window's width. The true value of gated radiotherapy can only be retained with smaller gating window with the expense of prolonging the treatment time.

Table 3. Comparison of our measured margin with the calculated margin using van Herk's margin recipe for 95\% isodose level. All values are in $\mathrm{mm}$.

\begin{tabular}{lccc|ccc}
\hline & \multicolumn{3}{c}{ Perspex } & \multicolumn{3}{c}{ Lung } \\
\cline { 2 - 7 } Amplitude & $\mathbf{1 0}$ & $\mathbf{2 0}$ & $\mathbf{4 0}$ & $\mathbf{1 0}$ & $\mathbf{2 0}$ & $\mathbf{4 0}$ \\
\hline $\mathrm{M}_{\text {static }}$ & 0.22 & 0.22 & 0.22 & 0.11 & 0.11 & 0.11 \\
$\mathrm{M}_{\text {non-gated }}$ & 2.46 & 4.29 & 10.27 & 1.40 & 2.59 & 7.17 \\
$\mathrm{M}_{\text {gated }}$ & 1.80 & 1.94 & 2.46 & 1.01 & 1.09 & 1.40 \\
& & & & & & \\
Non-gated & & & & & & \\
$\mathrm{M}_{\text {resp, calculated }}$ & 2.24 & 4.07 & 10.05 & 1.29 & 2.48 & 7.06 \\
$\mathrm{M}_{\text {resp, measurement }}$ & 3.14 & 4.54 & 10.80 & 1.96 & 3.40 & 8.02 \\
& & & & & & \\
Gated & & & & & & \\
$\mathrm{M}_{\text {resp, calculated }}$ & 1.58 & 1.72 & 2.24 & 0.90 & 0.97 & 1.29 \\
$\mathrm{M}_{\text {resp, measurement }}$ & 0.70 & 1.20 & 1.80 & 0.60 & 0.20 & 0.44 \\
\hline
\end{tabular}

\subsection{TPS calculation algorithms for interface dosimetry}

Three dose calculations available in Eclipse TPS for lung and Perspex interface dosimetry were evaluated for comparison against EBT2 film measurement. Figure 6 shows the dose profiles across the lung and Perspex interface in the moving phantom during static radiotherapy. All dose profiles were normalised to $100 \%$ at the isocentre.

Overall, the RMSEs of $6.21 \%, 3.32 \%, 2.62 \%$, and $1.73 \%$ were found for PBC, AAA $\mathrm{AXB}_{\mathrm{w}}$, and $\mathrm{AXB}_{\mathrm{m}}$, respectively. All algorithms were in agreement with the EBT2 film measurement in the Perspex media, except at the penumbra regions. Maximum deviations of $-5.45 \%, 4.29 \%, 3.98 \%$, and $-2.44 \%$ were observed for PBC, $\mathrm{AAA}, \mathrm{AXB}_{\mathrm{w}}$ and $\mathrm{AXB}_{\mathrm{m}}$, respectively within the central $80 \%$ of the radiation field.

In the lung media, excluding the penumbral region, $\mathrm{AAA}, \mathrm{AXB}_{\mathrm{w}}$ and $\mathrm{AXB}_{\mathrm{m}}$ were in agreement with EBT2 film measurement. The maximum deviations were $6.01 \%, 4.13 \%$, and $1.84 \%$ for $\mathrm{AAA}, \mathrm{AXB}_{\mathrm{w}}$, and $\mathrm{AXB}_{\mathrm{m}}$ respectively. Similar results were observed in previous studies that $\mathrm{AXB}_{\mathrm{m}}$ was in better agreement than AAA [20, 42]. PBC over-estimated the dose 
in lung media of up to $12.67 \%$. Large deviations were observed for all TPS calculation algorithms at the penumbral region. This is due to the dose volume averaging effect of the ionisation chamber during the commissioning of the TPS.

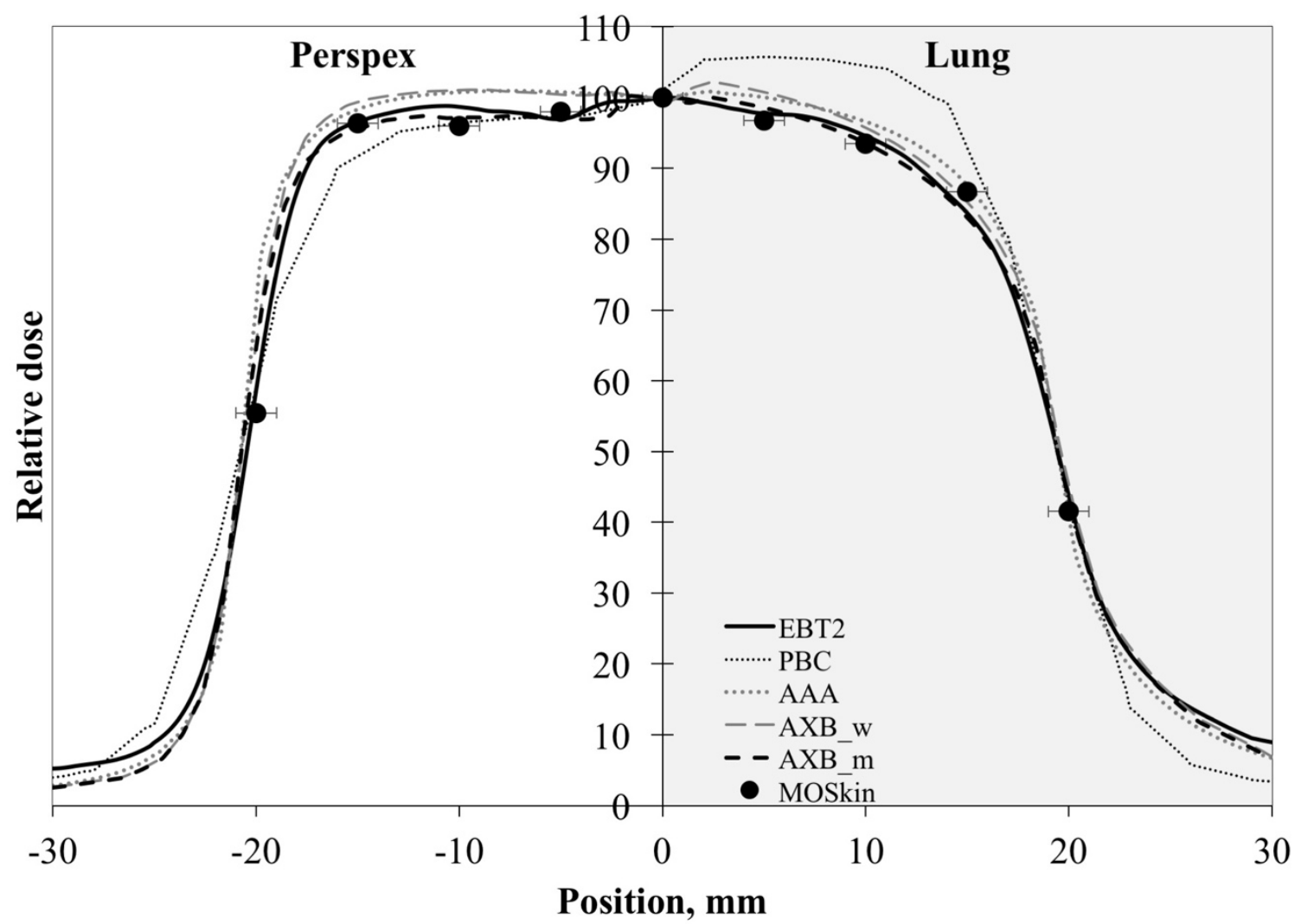

Figure 6. The measured and calculated dose profiles across the lung and Perspex interface during static radiotherapy.

It is known that accurate dose calculations for lung SBRT are challenging due to the lack of lateral scattered electronic equilibrium in the lungs. The PBC algorithm, which is a correction-based algorithm, accounted the tissue inhomogeneity based on the equivalent path length, without taking into account the change in the lateral electron transport [43-45]. It significantly over-estimated the dose near the lung and Perspex interface, especially in the lung media.The inhomogeneity correction was only accounted in the direction parallel to the incident beam. Our result was consistent with previous published data [18, 33, 43].

The AAA algorithm, which is a model-based algorithm, has lateral electron transport modelled as variable direction and considerably improved the dose accuracy in lung media $[43,46]$. The over-estimation of PBC in lung media was improved by AAA, with the maximum deviation of $12.76 \%$ reduced to $6.01 \%$. This result was comparable with the result reported by Han et al. [42] where average differences of $2.8 \%$ and $5.7 \%$ were observed between the lateral dose profile in heterogeneous slab phantom calculated by AAA and MC simulation for $6 \mathrm{MV}$ and $18 \mathrm{MV}$ photons, respectively.

The AXB algorithm is a grid-based linear Boltzman transport equation solver $[47,48]$ and has been proven to be able to predict the dose in inhomogeneous media with comparable 
accuracy to Monte Carlo method [49]. Our result shows that the dosimetric accuracy was further improved by AXB as compared to $\mathrm{PBC}$ and $\mathrm{AAA}$. The AXB was able to predict the dose in lung media with the deviation of $<5 \%$, with either reporting the dose in water $\left(\mathrm{AXB}_{\mathrm{w}}\right)$ or medium $\left(\mathrm{AXB}_{\mathrm{m}}\right)$. Similar result was observed in Han et al. [42] where average differences of $1.6 \%$ and $3.2 \%$ between the lateral dose profile in heterogeneous slab phantom calculated by $\mathrm{AXB}$ and MC simulation for $6 \mathrm{MV}$ and $18 \mathrm{MV}$ photons, respectively [42].

To understand the consequence of the accuracy of dose calculation algorithms near the interface region for margin generation, the positions of $95 \%$ isodose level for each calculation algorithms has been located and compared with the positions of $95 \%$ isodose level as measured using EBT2 film (Table 4). The positions of 95\% isodose level measured with EBT2 film during static radiotherapy were $-16.20 \mathrm{~mm}$ and $9.60 \mathrm{~mm}$ in Perspex and lung media, respectively. These positions were assumed to have adequate dose coverage with $95 \%$ isodose level at the edge of the target tumour volume. The PBC underestimated the dose coverage in Perspex media by $3.20 \mathrm{~mm}$ while overestimated the dose coverage in lung media by $5.0 \mathrm{~mm}$. Advanced dose calculation algorithms have shown to improve the dose accuracy near interface region, particularly in lung media. However, there were still some discrepancies compared to the measurement. both $\mathrm{AAA}$ and $\mathrm{AXB}_{\mathrm{w}}$ still over-estimated the dose coverage while $\mathrm{AXB}_{\mathrm{m}}$ underestimated the dose coverage in Perspex and lung media. To understand the actual dose of the corresponding position, the dose was measured with EBT2 film and shown in Table 4. Assuming the setup uncertainty for this measurement was $\pm 1 \mathrm{~mm}$, the average dose within $\pm 1 \mathrm{~mm}$ of the correspond position was determined. The overestimation of the dose coverage to the tumour will lead to a choice of a field size which is too small and subsequently lead to under-dosage to the target tumour. Therefore, the understanding and selection of the dose calculation algorithm is very important.

Table 4. Positions of 95\% isodose level calculated using different dose calculation algorithms. The right column shows the average measured dose over $\pm 1 \mathrm{~mm}$ of the corresponding position.

\begin{tabular}{lcc|cc}
\hline & \multicolumn{2}{c}{ Positions of 95\% isodose level, $\mathbf{~ m m}$} & \multicolumn{2}{c}{ EBT2 Measured dose, \% } \\
\cline { 2 - 5 } & Perspex & Lung & Perspex & Lung \\
\hline EBT2 & -16.20 & 9.60 & - & - \\
PBC & -13.00 & 14.60 & $99.07 \pm 0.38$ & $84.78 \pm 1.94$ \\
AAA & -17.00 & 11.40 & $91.97 \pm 2.91$ & $92.54 \pm 1.12$ \\
AXBw & -17.40 & 10.40 & $89.90 \pm 3.93$ & $94.04 \pm 0.88$ \\
AXBm & -15.60 & 8.80 & $95.75 \pm 0.96$ & $95.90 \pm 0.67$ \\
\hline
\end{tabular}

The accuracy of PBC and AAA are beam model dependent [50]. AXB showed better dose accuracy compared to $\mathrm{PBC}$ and $\mathrm{AAA}$, with a minimal dose difference between $\mathrm{AXB}_{\mathrm{w}}$ and $\mathrm{AXB}_{\mathrm{m}}$. Although the difference between $\mathrm{AXB}_{\mathrm{w}}$ and $\mathrm{AXB}_{\mathrm{m}}$ was minimal in most tissue, dose difference of up to $15 \%$ may be observed in bone region [42]. Therefore, the selection these two reporting modes is important especially when reporting the dose of inhomogeneous tissue. The default mode for $\mathrm{AXB}$ is dose to medium $\left(\mathrm{AXB}_{\mathrm{m}}\right)$ as it is a linear Boltzman transport equation solver for specific materials in patient. In most TPS, only one of these dose reporting mode is available. A thorough comparison between $\mathrm{AXB}_{\mathrm{w}}$ and $\mathrm{AXB}_{\mathrm{m}}$ is beyond the scope of this study. For dose calculation in lung media, better TPS dose calculation 
algorithms such as AAA or AXB are essentially within dosimetric expectation for planningrelated uncertainties. To note, not only the dose calculation algorithms itself will introduce errors, but the implementation of the algorithm in the TPS such as beam model parameters plays a role as well.

\section{Conclusion}

This study has explicitly investigated the dosimetric characteristics near interface region in a moving phantom during non-gated and gated radiotherapy. Dose smearing effect was observed during non-gated radiotherapy and more pronounced with larger respiratory amplitude. This effect can be reduced with gated radiotherapy, but it cannot be fully eliminated due to the residual motion within the gating windows. The residual motion is greater in larger gating window's width.

The dose smearing effect due to the respiratory motion which resulted in under-dosage inside the target tumour should be taken into account in radiotherapy, either by increasing the margin (motion encompassing technique) or using respiratory tracking system to gate the beam to the moving target (respiratory-gating). In motion encompassing technique for respiratory motion of $40 \mathrm{~mm}$, margins of at least $10.80 \mathrm{~mm}$ and $8.02 \mathrm{~mm}$ in Perspex and lung media, respectively are needed to ensure full dose coverage to the target tumour with 95\% isodose level. The margin can be furthered reduced by $1.80 \mathrm{~mm}$ and $0.44 \mathrm{~mm}$ in Perspex and lung media, respectively by using $25 \%$ gating window's width during gated radiotherapy. A small margin is still needed to compensate for the residual motion.

All PBC, AAA, and AXB showed a good agreement with EBT2 film measurement in the dose determination near the Perspex media. PBC showed an over-estimation of the dose in near the lung media compared EBT2 film measurement. The over-estimation of the dose near the lung media has been improved by using modern dose calculation algorithm, which AXB is more accurate compared to AAA. Therefore, it is essential to use better algorithm for dose determination near the lung interface.

The MOSkin detector has small sensitive volume, water-equivalent packaging and minimal perturbation effect is suitable for dose assessment near the interface region of 2 different media. This has been shown in the good agreement of The MOSkin detectors with the EBT2 film in the dose profile measurement during static and gated radiotherapy.

\section{References}

[1] Timmerman R, Paulus R, Galvin J, Michalski J, Straube W, Bradley J, et al. Stereotactic body radiation therapy for inoperable early stage lung cancer. Jama. 2010;303:1070-6.

[2] Seppenwoolde Y, Shirato H, Kitamura K, Shimizu S, van Herk M, Lebesque JV, et al. Precise and real-time measurement of 3D tumor motion in lung due to breathing and heartbeat, measured during radiotherapy. Int J Radiat Oncol Biol Phys. 2002;53:822-34. [3] Erridge SC, Seppenwoolde Y, Muller SH, van Herk M, De Jaeger K, Belderbos JS, et al. Portal imaging to assess set-up errors, tumor motion and tumor shrinkage during conformal radiotherapy of non-small cell lung cancer. Radiother Oncol. 2003;66:75-85. 
[4] Bortfeld T, Jiang SB, Rietzel E. Effects of motion on the total dose distribution. Semin Radiat Oncol. 2004;14:41-51.

[5] Keall PJ, Mageras GS, Balter JM, Emery RS, Forster KM, Jiang SB, et al. The management of respiratory motion in radiation oncology report of AAPM Task Group 76. Med Phys. 2006;33:3874-900.

[6] Korreman SS. Image-guided radiotherapy and motion management in lung cancer. $\mathrm{Br} \mathrm{J}$ Radiol. 2015;88:20150100.

[7] Saw CB, Brandner E, Selvaraj R, Chen H, Saiful Huq M, Heron DE. A review on the clinical implementation of respiratory-gated radiation therapy. Biomedical Imaging and Intervention Journal. 2007;3:e40.

[8] Giraud P, Houle A. Respiratory gating for radiotherapy: main technical aspects and clinical benefits. ISRN Pulmonology. 2013;2013.

[9] Keall PJ, Aun Ng J, O'Brien R, Colvill E, Huang CY, Rugaard Poulsen P, et al. The first clinical treatment with kilovoltage intrafraction monitoring (KIM): a real-time image guidance method. Med Phys. 2015;42:354-8.

[10] Petasecca M, Newall MK, Booth JT, Duncan M, Aldosari AH, Fuduli I, et al. MagicPlate-512: A 2D silicon detector array for quality assurance of stereotactic motion adaptive radiotherapy. Medical Physics. 2015;42:2992-3004.

[11] Berbeco RI, Nishioka S, Shirato H, Chen GT, Jiang SB. Residual motion of lung tumours in gated radiotherapy with external respiratory surrogates. Phys Med Biol. 2005;50:3655-67.

[12] Jiang SB. Technical aspects of image-guided respiration-gated radiation therapy. Med Dosim. 2006;31:141-51.

[13] Chen H, Wu A, Brandner ED, Heron DE, Huq MS, Yue NJ, et al. Dosimetric evaluations of the interplay effect in respiratory-gated intensity-modulated radiation therapy. Med Phys. 2009;36:893-903.

[14] Fuji H, Asada Y, Numano M, Yamashita H, Nishimura T, Hashimoto T, et al. Residual motion and duty time in respiratory gating radiotherapy using individualized or populationbased windows. Int J Radiat Oncol Biol Phys. 2009;75:564-70.

[15] Murphy MJ. Adaptive motion compensation in radiotherapy: CRC Press; 2011.

[16] Falk M, Pommer T, Keall P, Korreman S, Persson G, Poulsen P, et al. Motion management during IMAT treatment of mobile lung tumors-A comparison of MLC tracking and gated delivery. Medical Physics. 2014;41:101707.

[17] Van Dyk J, Keane TJ, Rider WD. Lung density as measured by computerized tomography: implications for radiotherapy. Int J Radiat Oncol Biol Phys. 1982;8:1363-72. [18] Haedinger U, Krieger T, Flentje M, Wulf J. Influence of calculation model on dose distribution in stereotactic radiotherapy for pulmonary targets. Int J Radiat Oncol Biol Phys. 2005;61:239-49.

[19] IAEA. Commissioning and Quality Assurance of Computerized Planning Systems for Radiation Treatment of Cancer. Vienna: INTERNATIONAL ATOMIC ENERGY AGENCY; 2004.

[20] Alhakeem EA, AlShaikh S, Rosenfeld AB, Zavgorodni SF. Comparative evaluation of modern dosimetry techniques near low-and high-density heterogeneities. Journal of Applied Clinical Medical Physics. 2015;16.

[21] Fogliata A, Cozzi L. Dose calculation algorithm accuracy for small fields in nonhomogeneous media: The lung SBRT case. Phys Med. 2016.

[22] Gershkevitsh E, Schmidt R, Velez G, Miller D, Korf E, Yip F, et al. Dosimetric verification of radiotherapy treatment planning systems: results of IAEA pilot study. Radiother Oncol. 2008;89:338-46.

[23] Metcalfe PE, Kron T, Hoban P. The physics of radiotherapy x-rays and electrons. 2007. 
[24] Tenn SE, Solberg TD, Medin PM. Targeting accuracy of an image guided gating system for stereotactic body radiotherapy. Phys Med Biol. 2005;50:5443-62.

[25] Jong WL, Wong JHD, Ng KH, Ung NM. Dose profile measurements during respiratorygated lung stereotactic radiotherapy: A phantom study. Journal of Physics: Conference Series. 2016;694:012015.

[26] Aland T, Kairn T, Kenny J. Evaluation of a Gafchromic EBT2 film dosimetry system for radiotherapy quality assurance. Australas Phys Eng Sci Med. 2011;34:251-60.

[27] Kwan IS, Rosenfeld AB, Qi ZY, Wilkinson D, Lerch MLF, Cutajar DL, et al. Skin dosimetry with new MOSFET detectors. Radiat Meas. 2008;43:929-32.

[28] Jong WL, Wong JHD, Ung NM, Ng KH, Ho GF, Cutajar D, et al. Characterization of MOSkin $^{\mathrm{TM}}$ Detector for In-vivo Skin Dose Measurement during Megavoltage Radiotherapy. J Appl Clin Med Phys. 2014;15:120-32.

[29] Hardcastle N, Soisson E, Metcalfe PE, Rosenfeld AB, Tome WA. Dosimetric verification of helical tomotherapy for total scalp irradiation. Med Phys. 2008;35:5061-8. [30] Jong WL, Ung NM, Vannyat A, Jamalludin Z, Rosenfeld A, Wong JH. "Edge-on" MOSkin detector for stereotactic beam measurement and verification. Phys Med. 2017;33:127-35.

[31] Klein EE, Hanley J, Bayouth J, Yin FF, Simon W, Dresser S, et al. Task Group 142 report: quality assurance of medical accelerators. Med Phys. 2009;36:4197-212.

[32] Ding GX, Duggan DM, Lu B, Hallahan DE, Cmelak A, Malcolm A, et al. Impact of inhomogeneity corrections on dose coverage in the treatment of lung cancer using stereotactic body radiation therapy. Med Phys. 2007;34:2985-94.

[33] da Rosa LA, Cardoso SC, Campos LT, Alves VG, Batista DV, Facure A. Percentage depth dose evaluation in heterogeneous media using thermoluminescent dosimetry. J Appl Clin Med Phys. 2010;11:2947.

[34] Hoban PW, Keal PJ, Round WH. The effect of density on the 10MV photon beam penumbra. Australas Phys Eng Sci Med. 1992;15:113-23.

[35] Kornelsen RO, Young ME. Changes in the dose-profile of a 10 MV x-ray beam within and beyond low density material. Med Phys. 1982;9:114-6.

[36] ICRU. Stopping powers for electrons and positrons. ICRU Report 37. 1984.

[37] Engelsman M, Sharp GC, Bortfeld T, Onimaru R, Shirato H. How much margin reduction is possible through gating or breath hold? Phys Med Biol. 2005;50:477-90.

[38] Low DA, Harms WB, Mutic S, Purdy JA. A technique for the quantitative evaluation of dose distributions. Med Phys. 1998;25:656-61.

[39] Venselaar J, Welleweerd H, Mijnheer B. Tolerances for the accuracy of photon beam dose calculations of treatment planning systems. Radiother Oncol. 2001;60:191-201.

[40] van Herk M. Errors and margins in radiotherapy. Semin Radiat Oncol. 2004;14:52-64. [41] van Herk M, Remeijer P, Rasch C, Lebesque JV. The probability of correct target dosage: dose-population histograms for deriving treatment margins in radiotherapy. Int $\mathrm{J}$ Radiat Oncol Biol Phys. 2000;47:1121-35.

[42] Han T, Mikell JK, Salehpour M, Mourtada F. Dosimetric comparison of Acuros XB deterministic radiation transport method with Monte Carlo and model-based convolution methods in heterogeneous media. Med Phys. 2011;38:2651-64.

[43] Fogliata A, Nicolini G, Clivio A, Vanetti E, Cozzi L. Dosimetric evaluation of Acuros XB Advanced Dose Calculation algorithm in heterogeneous media. Radiation Oncology (London, England). 2011;6:82-.

[44] Liu H, Zhuang T, Stephans K, Videtic G, Raithel S, Djemil T, et al. Dose differences in intensity-modulated radiotherapy plans calculated with pencil beam and Monte Carlo for lung SBRT. J Appl Clin Med Phys. 2015;16:5514. 
[45] Knoos T, Ceberg C, Weber L, Nilsson P. The dosimetric verification of a pencil beam based treatment planning system. Physics in Medicine and Biology. 1994;39:1609.

[46] Fogliata A, Nicolini G, Vanetti E, Clivio A, Cozzi L. Dosimetric validation of the anisotropic analytical algorithm for photon dose calculation: fundamental characterization in water. Phys Med Biol. 2006;51:1421-38.

[47] Fogliata A, Nicolini G, Clivio A, Vanetti E, Mancosu P, Cozzi L. Dosimetric validation of the Acuros XB Advanced Dose Calculation algorithm: fundamental characterization in water. Phys Med Biol. 2011;56:1879-904.

[48] Vassiliev ON, Wareing TA, McGhee J, Failla G, Salehpour MR, Mourtada F. Validation of a new grid-based Boltzmann equation solver for dose calculation in radiotherapy with photon beams. Phys Med Biol. 2010;55:581-98.

[49] Failla GA, Wareing T, Archambault Y, Thompson S. Acuros XB advanced dose calculation for the Eclipse treatment planning system. Palo Alto, CA: Varian Medical Systems. 2010.

[50] Panettieri V, Barsoum P, Westermark M, Brualla L, Lax I. AAA and PBC calculation accuracy in the surface build-up region in tangential beam treatments. Phantom and breast case study with the Monte Carlo code PENELOPE. Radiother Oncol. 2009;93:94-101. 